\title{
Temporal and spatial process: urbanisation driven by rural-urban migration in China, 1949-2010
}

\author{
Ming Guan \\ School of Economics, \\ Xuchang University, \\ 461000, Xuchang, China \\ and \\ School of Economics, \\ Henan University, \\ 475000, Kaifeng, China \\ E-mail: gming0604@sohu.com
}

\begin{abstract}
This study analyses the spatial and temporal changes in urbanisation driven by rural-urban migration in China. China began the socialist era as a very under-urbanised country relative to its level of development and that it has been eliminating this urbanisation gap during the post-1978 period. It is the large scale rural-urban migration that pushes rapid urban population growth and contributes to China's urban economy boom by providing cheap labour. Rural-urban migrant is the main source of urban population growth. Under the special political, social and economic circumstances, the historical trajectory of China's urbanisation in the past six decades is unique in the world. Examining its characteristics and experiences would produce valuable implications on its future development trends.
\end{abstract}

Keywords: urbanisation; rural-urban migration; temporal; spatial; China.

Reference to this paper should be made as follows: Guan, M. (2014) 'Temporal and spatial process: urbanisation driven by rural-urban migration in China, 1949-2010', Int. J. Migration and Residential Mobility, Vol. 1, No. 1, pp.50-71.

Biographical notes: Ming Guan is an Associate Professor and Director in Xuchang University. He received his Bachelor of Science in 1999 and Master of Economics in 2005 from Harbin Normal University, and his $\mathrm{PhD}$ in Management from Harbin Institute of Technology in 2009. He has published nearly 50 academic papers. He is now focusing on labour economics and development economics, especially on residential mobility, health-related quality of life and housing issues in China.

\section{Introduction}

Migration works as a cause or consequence of urban development (Berg et al., 1979). China's urbanisation patterns and policies since 1949 have been the focus of a good deal of attention. In China, four major factors affect the size of urban population and therefore the urbanisation level: the criteria for designating a settlement as urban, the physical and 
administrative boundaries of places so demarcated, the household registration (hukou) system and the urban status of floating people (Zhang and Zhao, 1998). Like other countries in the early stage of industrialisation, the rural-urban migration is the main source of urbanisation growth in the current China (Zhang and Song, 2003). The city in China has functioned not simply as a body of assets and property but more as the centre of economic and social transformation engineered by the state for both growth and non-growth considerations. China's post-reform experience contrasted sharply with its slow and even stagnated urban population growth in the 1960s and 1970s, when it sought its industrialisation goal under a central planning system. Perhaps because of its uniqueness of size and development experience, China's urbanisation and rural to urban migration have remained a topic of great interest (Wu, 1994).

There are many factors influencing people to move or relocate to another region within China. The primary reason is life quality lag between urban and rural areas. Since initialisation of the socialist era, China remained as an agriculture economy with the predominant majority living in rural area for hundreds of years. It is the large scale rural-urban migration that pushes rapid urban population growth and contributes to urban economy boom by providing cheap labour. Rural-urban migrant is the main source of urban population growth. Zhao (2003) confirms that single young men from families with more labour, less land and more young children are more likely to migrate. Furthermore, village income has an inverted - $U$ shaped effect on migration and availability of non-farm employment reduces the probability of migration. The number of experienced migrants is found to have significant and positive effect on subsequent migration, but the effect disappears after the migrants return, implying that income differentials alone are not sufficient in inducing labour migration, but actual help in the process of migration is more valuable in promoting migration. Wu (2010) finds significant self-selection in migration. Youths, men, better-educated individuals and those in good health are more likely to migrate. Cheng and Ma (2006) indicate that the push from towns, especially the development of industrial technology in urban areas, is the key reason causing rural labour migration from the rural areas to the urban areas. Meanwhile, further popularising universal education in rural areas will have a deep influence on this migration. Besides, gender family income and region gap also affect rural workers' migration. From 1949 to now, China's current state-supported pension system and other social welfare provisions are highly urban biased. There is very limited social welfare provision for the rural persons (Peng, 2004). The level of urbanisation is usually measured by the share of urban population in total population. See Figure 1. China's urbanisation experiences a fluctuant trajectory, although the main trend is continuous urban population growth.

China strongly restricts rural-urban migration, resulting in a well acknowledged surplus of labour in agriculture. But migration is also restricted within sectors. Au and Henderson (2006) argue that these intra-sector restrictions lead to insufficient agglomeration of economic activity in both the rural industrial and urban sectors, with resulting first order losses in GDP. Under-urbanisation is the achievement of a high industrial growth without a parallel growth of urban population (Zhang and Zhao, 2003). China's urbanisation gap appeared and grew in the late period of reform despite mass migration from rural to urban areas. This growing urbanisation lag is mainly due to the slow pace in eliminating restrictions on rural-urban migration during a period of rapid economic growth. The emerging urbanisation lag entails significant economic costs in employment and retards economic growth (Chang and Brada, 2006). 
Figure 1 Fluctuant trajectory of China's urbanisation (see online version for colours)

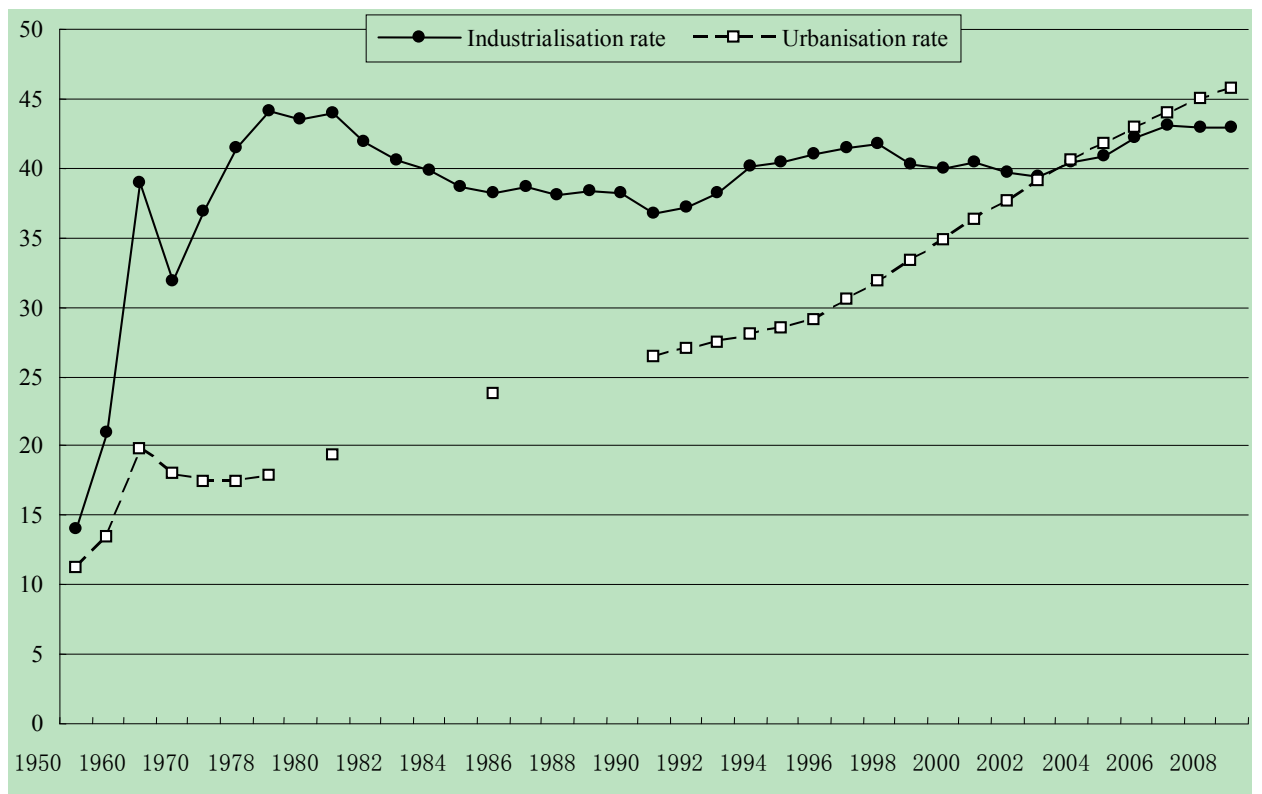

Source: 2001-2009 China Statistics Yearbook

During the transition, Chinese peasants are made more vulnerable and must rely on migrant work for survival, but their low institutional status relegates them to outsider status in urban areas. These circumstances, with socio-cultural traditions constraining women's mobility and endorse stratifications, have enabled the development of a labour regime that fosters segmentation and division of labour. Peasant migrants' reliance on social network further reinforces segregation in the urban labour market (Fan, 2003). Both the large scale of migration and the reducing importance of the agriculture sector have impacts on urban development patters. New migrants with limited skills are new urban poor, and their housing need from the demand side is one of the main factors to city's spatial reorganisation. As migration restrictions have eased, the pattern has changed as we will see below, with high in-migration to the largest cities in this decade. According to Xian (2001) and Cai et al. (2002), the rate of rural labour transfer to offfarm jobs has accelerated notably in recent years.

$\mathrm{Gu}$ et al. (2012) argue that in comparison with the Western developed countries and most developing countries, Chinese urbanisation faces more complicated backgrounds and more problems. The theories and framework of urbanisation developed in both developed and most developing countries cannot be directly applied in China. The research purpose in China is to form unique theories on urbanisation based on actual conditions and characteristics in this country and the research shall adopt a multiple approach focusing on the impact of the progress of society, economy, population, politics, culture, environment, technology and public policies on Chinese urbanisation. 
This paper is an examination of the fundamentals of China's urbanisation in the last six decades. Section 2 will provide a briefly introduce evolution of urban administration. Section 3 will document temporal dimension of urbanisation and will examine the profile of the migrants. Section 4 will review spatial dimension of urbanisation, including city-level migration, province-level migration, region-level migration and arable land shrinkage. Section 5 will offer some comments and thoughts on further research issues and will conclude the paper.

\section{Administration in migration}

China's urbanisation and urban development have been heavily regulated and controlled by the state government. It is observed that China had deliberately adopted a series of 'anti-urbanisation' policies measures to 'economise' on urbanisation without negatively affecting industrialisation (Chan, 1992). The hukou system, which emerged in the course of a decade, was integral to the collective transformation of the countryside, to a demographic strategy that restricted urbanisation, and to the redefinition of city-countryside and state-society relations (Cheng and Selden, 1994). A household registration (hukou) system was established in 1954 to stop unauthorised migration from the countryside to the cities and uncontrolled growth of large cities. It divided the population into agricultural (nongye renkou) and non-agricultural (fei nongye renkou), which was used in conjunction with the food rationing system to regulate the monthly quotas of foodstuffs, consumables, and consumer durables (Kirkby, 1985). China's hukou system became law in 1958, when the National People's Congress passed its 'Regulations on Household Registration in the People's Republic of China'. Under these regulations, every Chinese citizen is assigned a hukou location (hukou suozaidi) and an 'agricultural' (rural) or 'non-agricultural' (urban) hukou classification (hukou leibie) (Yu, 2002; Wang, 2005). The hukou system in China is similar to an internal passport system. ${ }^{1}$

China has a relative decentralised but hierarchical structure that makes it difficult to define what constitutes a city as opposed to rural area. The central government in Beijing manages this huge country at the level of province, prefecture, county, town, and township. Chinese cities are classified in four levels according to their relative importance in the administrative structure. The administrative areas in China can be divided into four levels, namely: the central government; provinces and municipalities; cities, counties and districts; townships and towns under the jurisdiction of counties, and districts and lower level counties under the jurisdiction of cities. ${ }^{2}$ Definition of 'city' in China has not followed a fixed way since 1949. According to Kojma (1995), since taking power in 1949, the Chinese Government has defined and redefined the definition of 'city' three times. In the first (November 1955), the State Council decided on the criteria for urban-rural zoning. The second time (December 1963), cities were defined when the Central Committee of the Chinese Communist Party and the State Council issued a directive adjusting the official definition of cities and towns in order to reduce the number of designated towns and to disqualify many of the suburban areas of cities from urban status. The third change (October 1984), Civil Service Department allow the agricultural population to transfer their family registers from rural areas to officially designated towns (but not to designated cities) and allow them to take up non-agricultural jobs. The migrants who have transferred their family registers to designated towns are 
now under the control of city residential authority. China's urban and rural districts have thus been administratively separated, with the rural population placed under the control of the village authority and the urban population under the city residential authority. The third change in definition took place in 1986 when "On Ajustment of Standards for City Designation and Conditions for City to Administer Counties" was launched. Since china entered the decade of reforms in 1980s and urban growth was encouraged, a set of more relaxed city and town designation criteria was employed by the Ministry of Civil Affairs. In 1993, the fourth change in city designation was approved by the State Council. Counties are divided into three classes according to their population density before transforming the initial county into designated city. Among the 12 criteria, the scale and ratio of non-agricultural population are still the most important items.

The definition of urban population in China has change in each of the five national Censuses (Liu et al., 2003). In the first 1953 census, urban population included all population, agricultural and non-agricultural, residing in designated cities and towns. In the second 1964 census the total urban population was limited to the non-agricultural population within the designated urban places. The third 1982 census stepped back in the first 1953 census definition of urban population; for the government had realised that the 1963 definition was too limiting and might cause under-estimation on Chinas urbanisation level. The fourth 1990 national census adopted a compromise definition. The urban population is composed of:

a all population, including agricultural and non-agricultural, of cities with urban districts, which is in line with the 1982 definition

b the non-agricultural population with stays longer than one-year was included into the urban population.

The fifth 2000 national census to make some corrections the 1990 census definition was further improved, mainly in the following two aspects:

1 Only in those urban districts, cities and towns with a population density higher than 1,500 persons per $\mathrm{km}^{2}$, all population is regarded as urban population. While with a population density lower than 1,500 persons per $\mathrm{km}^{2}$, only the population that lives in streets, town sites, and adjacent villages is counted as urban population.

2 Immigrants without hukou but who reside in cities and towns longer than six-month, rather than one year in the fourth census, are accounted as local urban population (Zhou and Ma, 2003).

In the 1990 census, the resident population was composed of the population who had local hukou and the non-hukou population who had been in the locale for at least one year prior to the census. Geographically, all 'districts' under provincial- and prefectural-level cities were classified as urban. For county-level cities and towns, only areas where there were Residents' Committees were deemed urban. The 2000 definition has introduced three new elements in defining urban areas at various geographic levels:

a whether or not an area has an average population density of 1,500/sq.km

b whether or not the local government is located in the area

c whether or not the area is contiguous to an area where the local government is located (Chan and $\mathrm{Hu}, 2003)$. 
Due to the frequent changes of criteria for city and town designation and official urban population definition, many international scholars therefore regarded the size of China's urban population to be an 'enigma' (Liu et al., 2003; Shen, 1995).

In urbanisation of post-reform China, three paradoxical dynamics appear: a leap forward of urbanisation concurrent with the under-urbanised feature, the massive and sustained flow of rural-to-urban migration concomitant with the bulk of migrants without urban citizenship, and the phenomenal reorganisation of urban space and the proliferating addition of new cities with inclusion of ample rural attributes (Zhang, 2008). Shen et al. (2006) argues that a comprehensive dual-track urbanisation approach is more realistic for the study of urbanisation in the transitional economy of post-reform China with mixed characters of an old planned economy and an emerging market economy. The dual-track model of urbanisation is a significant departure from the Maoist model of Chinese urbanisation.

\section{Temporal dimension of urbanisation}

According to Li and Piachaud (2006), China urbanisation experiences three mode stages: planned and controlled urbanisation, free-market development and balanced social development. Inspired by Schoppa (2000), Communist Chinese history can be divided into several phases: the Mao era (1949-1978), the Deng era (1978-1992), the Jiang era (1992-2002) and the Hu era (2002-). From 1950 to 1978, rural-urban migration in China was driven by volatile central government economic and social policy. From 1978 to 2008, rural-urban migration in China was driven by market force.

\subsection{The Mao era}

Prior to the 1978 economic reforms, the system of cities created by the Maoist regime was dominated by large and extra-large cities because of the imperatives of optimum industrialisation. The ability of the government to exert a strong influence on urban development was mainly through population control and resource allocation. A superimposed dual-track system of urban settlements integrating the Maoist legacy of large city dominance at the top with the rapidly expanding component of small cities and towns in the bottom is quickly taking shape to characterise China's urban development and urbanisation (Lin, 2002). In the Mao era 'Chinese Model' have been the massive 'rustication' movements, the recruitment of large numbers of city dwellers to work in rural areas, strict controls on rural-urban migration through food rationing and household registration, and the expansion of rural employment through the development of rural industries (Chan and $\mathrm{Xu}, 1985$ ).

When the People's Republic of China was established in 1949, 7.3\% of the total population lived in cities. Between 1953 and 1956, 19.8 million people had migrated to the cities. This 'blind outflow of rural population' (nongcun renkou mangmu wailiu) gravely threatened the industrialisation strategy outlined above, and in 1955 Shanghai expelled half a million peasants (Cheng and Selden, 1994). During the 'First Five-year Plan' (1953-1957), many new industrial-mine cities have been established driving by 156 key projects, for example textile machinery city, such as Yuci; new-coal city, such as Jixi, Shuangyashan, Jiaozuo, Pingdingshan, Hebi; new-steel city, such as Maanshan; new-oil city, such as Yumen. Many old city has been improved and extended into 
industrial cities, such as Wuhan, Chengdu, Taiyuan, Xian, Luoyang, Lanzhou; established middle-medium cities, such as Anshan, Benxi, Qiqihar, large cities, such as Harbin, Changchun. At the end of 1957, China has 176 cities, than in 1949 grows 33.3\%. The average growth per year is $10 \%$; urban population increase to 70.77 million, than in 1949 grows $79.2 \%$, average per year grows $19.9 \%$. Proportion of urban population in nation increases to $10.9 \%, 3.3 \%$ more than in 1949 .

During the second five-year planning, urban development shows change from expansion to deflation. After 'Great Leap Forward (GLF)', city number increase in 1957 from 176 to in 1961 to 208 , grows $18.2 \%$; urban population increase from 70.77 million to 101.32 million, grows $43.2 \%$; proportion of urban population accounting for national population increase from $10.9 \%$ to $15.4 \%$. In 1958, China launched GLF and used surplus rural labour for local industrialisation and the improvement of the agricultural superstructure (Gray, 2006). Under the GLF policies, communes were implemented in the countryside. There was over-reporting of production to please party officials, which lead to over-consumption, finally resulting in 1959-1961 Chinese Great Famine where millions died. Due to highly uneven regional distribution of the famine (Yang, 1996), food shortage (Lin and Yang, 2000), urban bias in food allocation (Lin and Yang, 2000), urban areas suffered much less from famine than did rural areas. At the same time, the rigorously implemented residence registration (Hukou) system prevented rural people from migrating to urban areas. The famine in 1958-1961 is now recognised as the worst in human history. It has been estimated that the famine caused excess deaths of some 30 million of people and lost births of more than 30 million, mostly in rural areas (Ashton et al., 1984).

Agricultural collectivisation of $1955-1956$ in China has proved to be remarkably successful in further releasing industrial growth from the agricultural constraint (Kueh, 2006). Starting in 1961, migration reversed, as an attempt to deal with food shortage problems and upheaval in the commune sector. An urban centre losing its city status would revert to its original status as a county or town. Many factories were moved from coastal and big cities to under developed areas (Kim, 1988). At the beginning of 1962, China entered adjustment period of national economy and abolished many cities. Till 1965, China had 168 cities, compared with 1961, decrease by $20 \%$. Municipals established in the First Five-year Plan period are restored to counties; part of prefecture-level cities are downgraded as county-level cities, stopped and suspended a large number of construction projects, mobilise about 25 million staff to return countryside, urban population in 1961 from 101.32 million decreases to 88.58 million, decrease by $12.6 \%$; proportion of urban population decreases from $15.4 \%$ to $12.2 \%$.

The criteria for city and town designation were raised and a large amount of surplus urban population was deported into rural areas. It is estimated that around 18 million urban employees or 26 million urban populations were laid-off while the majority of them were deported into rural areas (Sun, 1996; Xu et al., 1999). In this period, the number of designated cities decreased from 208 in 1961 to 168 in 1965 and the net urban-rural migrants (after reducing the size of rural-urban migrants) were more than 9 million. Therefore, the total urban population in the end of 1965 was even a bit less than that in the beginning of 1961 and the urbanisation level declined from $19.75 \%$ in the beginning of 1961 to $17.98 \%$ in the end of 1965 . 
China came into Great Proletarian Cultural Revolution (GPCR) period. In the latter half of the 1960s, the Third Front program dispersed industries from the urban centres in the East and Northeast to the interior provinces, especially the southwestern region, to increase their survival chances in the event of war and to plant the seeds of industrial capability throughout the country (Naughton, 1988). This was followed by efforts to build small scale rural industries, and some decentralisation of economic decision making to provincial or county level agencies (Riskin, 1987). For the strategic consideration of national defence, most of the new cities were developed in the central and western interior rather than the eastern coast. In the beginning of GPCR, the large-scale movement of 'going to the rural and mountainous areas' was promoted by China's Government aiming to re-educate intellectuals and urban youths and in part to maintain social stability and to alleviate ongoing problems of urban unemployment. It was estimated that more than 16 million urban youths and 3 to 5 million intellectuals and cadres were deported to rural areas (Sun, 1996; Xu et al., 1999). However, the movement gradually came to stop in 1971 and the rural to urban migrants began to increase. In 1965, the urbanisation level reached to $18 \%$, but the Culture Revolution as a political movement again forced city residents moving to countryside, which made the urbanisation level dropped to $17.3 \%$ in 1975 .

\subsection{The Deng era}

The post-1978 era was the increase in the number of cities. There was a more relaxed attitude towards the establishment of cities. The granting of city status was also used as a mechanism to help local authorities to attract foreign investment. As a result, the total number of cities jumped rapidly from 194 in 1978 to 467 in 1990 and the city population (non-agricultural population in cities proper) soared from 84.1 million in 1978 to 150.38 million in 1990. A relatively large number of small and medium-sized cities were added to the city system. As a result, there has been a decline in the proportion of large cities and an increase in the proportion of small cities (Yeh and Xu, 1984). Since 1978, China has shifted its top priority to economic growth, the government gradually relaxed restrictions which created the history's largest flow of rural-urban migration in the world. Some factors contribute to the migration. First is Special Economic Zones. Special Economic Zones were founded by the central government under Deng Xiaoping in the early 1980s. Since then, many cities in coastal regions began to recruit rural labours in private-owned firms and foreign-owned firms. In the mid-1980s, China lowered the standards that it had set for towns and cities to be considered urban, this boosted (and distorted) the level of urbanisation. In the late-1980s, Hukou system relaxed and surge of peasants begin to migrate to cities. During the 1980s, the inflow of foreign direct investment created massive employment opportunities, which fostered urban population growth. China's urbanisation is highly localised, with less long-distance migration. Localised migration was part of 1982 Five Year Plan - the idea of 'leave the land but not the village' and absorb any migrants into nearby towns, deflecting migrants away from the largest cities. The result of highly localised migration is diffuse urbanisation, leaving most cities in China too small to exploit urban agglomeration economies efficiently, thereby limiting urban productivity gains and economic growth. Table 1 shows China yearly migration scale in the 1980 s. 
Table 1 China yearly migration scale in the 1980 s, unit: 10,000

\begin{tabular}{lccc}
\hline Year & Interprovince migration & Intraprovince migration & Total \\
\hline $1982-1983$ & 78.5 & 284.3 & 362.8 \\
$1983-1984$ & 104.8 & 410.7 & 515.5 \\
$1984-1985$ & 135.2 & 560.6 & 695.8 \\
$1985-1986$ & 168.1 & 622.2 & 790.3 \\
$1985-1990$ & 213.3 & 460.5 & 673.8 \\
\hline
\end{tabular}

Source: Gu and Liu (2000)

Chinese towns have been growing rapidly since economic reforms were initiated in 1979 (Lin, 1993). China's de jure urbanisation level more than doubled in the five years between 1982 and 1987, jumping from $20.8 \%$ to $46.6 \%$. The increase was largely the result of an increase in the number of urban towns since the mid 1984 relaxation of criteria for urban town designation. In fact due to the post-1984 governing system of 'town administering village' (zhen guan cun), many newly designated urban towns (and some existing towns as well) have enlarged their administrative territories to include a huge number of agricultural residents in their official urban population (Lee, 1989). Agricultural labour in China peaked in 1991 and declined steadily thereafter. From 1978 to 1990 , the urban population increased dramatically to $37 \%$ of the total population. This large jump resulted from a combination of factors. In 1983, communes were abolished and townships were revived. In the early 1980s, most of Chinese youth (ZhiQing) returned from rural areas back to cities. Part of them passed the college entrance examination. ${ }^{3}$ Numerous former rural students who studied hard to succeed on university entrance exams and left their villages, eventually moving on to urban jobs.

With respect to the national contribution in terms of economic efficiency achieved by cities of different sizes, Zhang (1991) indicate that, although lower order cities (especially small towns) indisputably prove to be of great assistance to the national economy, chiefly in absorbing the enormous surplus labour force from rural areas and alleviating the ponderous pressure of population influx upon giant cities, yet under no circumstances can they generate substantial productivity growth, originating from agglomeration economies characteristic of large metropolises.

\subsection{The Jiang era}

In 1978-1999, China has experienced a rapid and unprecedented process of urbanisation, created by the history's largest flow of rural-urban migration in the world. Zhang and Song (2003) find that:

a rural-urban migration made dominant contributions to Chinese urban population growth

b while moving together with the Chinese economy, the causal link runs from economic growth to migration, not vice versa

c interprovince migrants were encouraged by the rural-urban income gap and discouraged by their geographic distances to destinations

$\mathrm{d}$ the amount of intraprovince migrants is positively related to rural-urban income gap and urban population in that province. 
Even as recently as 1990, urbanisation then started taking off. This is urbanisation from within, although overall local absolute agricultural employment in cities grew modestly from 1990 to 1996. In particular are shorter-term or longer-term migrants working in the city, who either live in the city but are not counted in population enumeration or who cannot obtain housing within the city and reside just beyond the boundaries of urban districts (in often 'illegal' rural housing). In the 1990s, half of China's increased urbanisation simply involved local reorganisation, or reclassification of 'rural' areas as cities. During the 1990s, massive inflows of capital and foreign direct investment resulted in the transformation of a rural-based economy into an industry-based export economy that is characterised by labour-intensive production processes that consume large tracts of land and that have spurred substantial rural-urban migration (Sit and Yang, 1997). Migration is an increasingly effective factor of population redistribution and that it has a strong relationship with regional development. Regional divergence in economic development during the 1990s was accompanied by a marked increase in interprovincial migration and sharply concentrated migration flows, especially from relatively poor central and western provinces to the rapidly growing eastern region (Fan, 2005). While China has mega-cities such as Shanghai, Beijing and Guangzhou, in 1997, many prefecture-level cities were about half their efficient sizes. A doubling of the populations in such cities would lead to 20 to $35 \%$ increases in real output per worker. Although some cities have experienced heavy in-migration in the last few years, it seems the case that much of China still has too many cities with too few people (Au and Henderson, 2006). With the abolishment of the food rationing system in the early 1990s, food products could be bought freely in the urban market. A high degree of gender segregation among rural-urban migrants exists in the urban labour market, that peasant women's urban work opportunities are short-lived, and that upon marriage women migrants are relegated back to the village and to the 'inside', in part to sustain gender division of labour as a household strategy (Fan, 2003). ${ }^{4}$

While a large number of rural labourers transferred to non-farm activities during the 1980 s, most of them remained in their hometowns. Woo et al. (1994) find zero TFP growth in state-owned enterprises and positive TFP growth in town and village enterprises. The transfer of rural labourers during that period was characterised as 'leaving the land but not countryside'. Rural labour transfer was bolstered by policies designed to increase rural employment opportunities and raise rural income without threatening urban sector food supply and stability. Unlike population registration systems in many other countries, the Chinese system was designed not merely to provide population statistics and identify personal status, but also directly to regulate population distribution and serve many other important objectives desired by the state. In fact, the hukou system is one of the major tools of social control employed by the state. Its functions go far beyond simply controlling population mobility (Chan and Zhang, 1999). The Fifth National Population Census of China, in 2000, estimated that there were over 120 million internal migrant workers in cities, while other estimates range from 100 to 200 million persons (Lavely, 2001).

Since the late 1990s, many local governments (cities and towns) have now received full power and discretion to set their own admission criteria and the number of new permanent hukou each unit will accept each year; there is no longer a quota imposed by the central government (Chan and Buckingham, 2008). As of today, hukou reform is incomplete and its progress varies across provinces and even cities. In general, local situations fall into one of the three models (Cai, 2003): 
1 in over 20,000 small towns, applicants may receive local registration if they have a permanent source of living and housing in the locality

2 in many medium-size cities, including a few province capitals, requirements for gaining hukou status have been significantly reduced; some just require a long-term work contract

3 in few mega-cities such as Beijing and Shanghai, obtaining hukou remains very difficult.

It is doubtful that radical liberalisation will occur so long as loss of the power to grant or withdraw hukou registration is deemed a threat to the incumbent government's political power.

Zhao et al. (2003) argues that after China's entry of WTO, urbanisation economies and urbanisation agglomeration prevail, Chinese large cities will continue to outperform the small cities and so the dominance of large cities will continue.

\subsection{The Hu era}

With the 'push-and-pull' of market forces, rural populations are moving in bulk to urban areas where they are devoid of social guarantees. According to China city statistical yearbook 2009, one percentage increase of urbanisation level needs 15 million rural persons enter cities. Since the 2000s, central government in order to meet the need for cheap labour in urban manufacturing industry and the pressure of rural poverty reduction relax hukou system. At the same time, agriculture reduces its importance in China's national economy, although about one half of Chinese labour force is still working in farm field. ${ }^{5}$ A household income survey for China in 2002 shows incorporating the migrants into the urban population raises urban inequality and reduces the urban-rural gap somewhat, but leaves the latter still very high by international standards (Khan and Riskin, 2005). China came into building harmonious socialist society period. ${ }^{6}$ China's Eleventh Five-Year Plan (2006-2010) advances the concept of "engaging in industries and farming, circular flows between city and countryside" (yigong yinong, chengxiang shuangxiang liudong) for rural-urban migrants. While stating that migrant workers' labour rights should be protected, ${ }^{7}$ the plan does not favour an all-out removal of restrictions on migration. Rather, it encourages the permanent settlement of rural migrants in medium and small cities as well as small towns, but insists that super-large cities should control their population growth (Fan, 2006). China's rapid urbanisation produces marginalisation of rural migrant workers in urban cities in China (Wong et al., 2007), urban village (Liu et al., 2010). ${ }^{8}$ In recently years, how to resolve issues related to rural labour force migration has become the most urgent and essential task for the Chinese Government.

According to China City Statistical Yearbook, 2009, migrant population mainly is driven by economic benefit. Nearly, 90 percentage immigrated population flow for making a living. Of them, $68.3 \%$ immigrant populations enter cities for a job, $8.8 \%$ for business, and $7.7 \%$ for housekeeping. Because large cities and mega-cities are lack of acceptance ability for immigrant population, small- and medium-sized cities gradually become first choice for immigrated population. According to 2008 sampling, $8.2 \%$ chose mega-cities, such as municipality directly under the central government, $18.5 \%$ chose 
province-cities, $33.4 \%$ chose prefecture-level city, $19.8 \%$ chose county-level city, $14.6 \%$ chose organic town. Positive selection in migration is related to the alternatives of not working and local farm work, and negative selection is related to local non-farm work. More importantly, different self-selection between individuals who have moved as pioneers and migrants from households in which other members have already migrated (Wu, 2010).

\section{Spatial dimension of urbanisation}

Internal migration is an important factor in the spatial distribution of population. The urbanisation driven by migration proceeds in China at the city-level, province-level and region-level, shrinks the farmlands.

\subsection{City-level migration}

According to Berg et al. (1979), urban GDP grows with immigration. And, growth of income in the destination location may be directly important determinants of urban acceptance. According to GDP value, the immigrating city can be classified as:

1 GDP in the city is over 500 billion yuan

2 GDP in the city is 200 billion to 500 billion yuan

3 GDP in the city is 100 billion to 200 billion yuan

4 GDP in the city is below 100 billion.

Table 2 shows the relationship among urban GDP, immigrant population and GDP type. According China City Statistical Yearbook 2009, urban GDP has relationship with migration volume. Cities in 2007 with maximum volume of rural migrants are in turn Shenzhen, Dongguan, Shanghai and Beijing. But cities with maximum GDP are in turn Shanghai, Beijing, Guangzhou, and Shenzhen.

According to China City Statistical Yearbook, 2009, constrained by resources and environment, life cost and urban population control policy, some main immigrant cities, such as Beijing, Shanghai, Guangzhou and Dongguan, show the trend of immigration slowdown. By analysing the difference among the cities, Li et al. (2008) concluded,

1 the growth of the GDP and per capita GDP of the cities are mostly not steady going

2 the middle and big cities are more-sensitive responders to the growth of economy, whereas the small and mega cities are less-sensitive responders

3 the sizes of southwest cities have a higher speed than those of northwest ones, and furthermore, the differences between them are still increasing.

It is found that coastal provinces encountered greater pressure and challenges in dealing with the accommodation of migrants who were mainly from inland provinces. In contrast, inland provinces have relatively less pressure from migrants (Chen et al., 2011). 
Table 2 Urban GDP, immigrant population and type

\begin{tabular}{|c|c|c|c|}
\hline City & $\begin{array}{c}G D P \\
\text { (hundred million) }\end{array}$ & $\begin{array}{c}\text { Immigrant population } \\
\text { (ten thousand) }\end{array}$ & GDP type \\
\hline Beijing & 9,353 & 420 & I type \\
\hline Tianjin & 5,050 & 156 & I type \\
\hline Shanghai & 12,189 & 479 & I type \\
\hline Guangzhou & 7,109 & 232 & I type \\
\hline Shenzhen & 6,802 & 650 & I type \\
\hline Suzhou & 5,701 & 258 & I type \\
\hline Nanjing & 3,284 & 124 & II type \\
\hline Wuxi & 3,859 & 137 & II type \\
\hline Foshan & 3,605 & 231 & II type \\
\hline dongguan & 3,152 & 524 & II type \\
\hline Nantong & 2,112 & -48 & II type \\
\hline Hangzhou & 4,100 & 114 & II type \\
\hline Ningbo & 3,435 & 125 & II type \\
\hline Jiaxing & 1,585 & 82 & III type \\
\hline Shaoxing & 1,972 & 22 & III type \\
\hline Táizhou & 1,722 & 4 & III type \\
\hline Changzhou & 1,881 & 78 & III type \\
\hline Zhenjiang & 1,207 & 33 & III type \\
\hline Yangzhou & 1,312 & -13 & III type \\
\hline Jiangmen & 1,107 & 25 & III type \\
\hline Tàizhou & 1,202 & -43 & III type \\
\hline Zhongshan & 1,238 & 106 & III type \\
\hline Huizhou & 1,093 & 75 & III type \\
\hline Zhaoqing & 414 & 7 & IV type \\
\hline Huzhou & 892 & 22 & IV type \\
\hline Zhoushan & 409 & 7 & IV type \\
\hline Zhuhai & 896 & 49 & IV type \\
\hline
\end{tabular}

Note: Because Hebei province is outflowing province in 2007, cities in Hebei province are not listed.

Source: China city Statistical Yearbook, 2009

\subsection{Province-level migration}

With the development of regional integration, interprovincial immigrants have remarkably regional choices. According to data from 15 outmigrant provinces with over 10 million labours (Sichuan, Henan, Anhui, Jiangsu, Shandong, Yunan, Guangxi, Hunan, Shanxi, Gansu, Jiangxi, Hebei, Hubei, Heilongjiang and Chongqing), interprovincial immigrants in 2008 cities in eastern region than in 2000 increased $92 \%$, interprovincial immigrants flowing into middle-western region change little, interprovincial immigrants 
cities in middle-western region shows decline trend. It implies, part of interprovincial immigrants who initially choose cities in middle-western region immigrated population flow into eastern region. Guangdong is the first choice for immigrant population, but its growth velocity is smaller than Yangtze River Delta. Comparing 2008 with 2000, Guangdong province immigrant population increases by 0.9 times. Comparing 2000 with 1995, in Guangdong, immigrant population increase by 4.9 times, rate of increase decreased by $81.6 \%$; in 2008, interprovincial flowing population in Yangtze River Delta in 2000 increase by 1.0 times, only in 2000 than in 1995 rate of increase decreased by $50 \%$, flowing population from Jiangsu province, Zhejiang province and Shandong province into Guangdong in eight years reduces $26.1 \%$.

Table 3 Immigration in selected provinces in 2000 and 2008 unit: \% and 10,000 persons

\begin{tabular}{lccccccc}
\hline & 2000 & & & \multicolumn{3}{c}{2008} \\
\cline { 1 - 2 } \cline { 5 - 7 } Province & $\begin{array}{c}\text { Immigrant } \\
\text { population }\end{array}$ & Growth rate & & Province & $\begin{array}{c}\text { Interprovince } \\
\text { migrants }\end{array}$ & $\begin{array}{c}\text { Intraprovince } \\
\text { migrants }\end{array}$ \\
\hline Beijing & 260.35 & 34.18 & & Beijing & 400 & 20 \\
Tianjin & 79.09 & 22.15 & & Shanghai & 600 & 30 \\
Hebei & 213.18 & 7.32 & & Jiangsu & 500 & 950 \\
Shanghai & 436.01 & 32.82 & & Zhejiang & 900 & 500 \\
Jiangsu & 500.74 & 12.46 & & Fujian & 270 & 400 \\
Zhejiang & 542.63 & 18.72 & & Shandong & 170 & 1,000 \\
Guangdong & $2,105.41$ & 29.69 & & Guangdong & 3,100 & 1,400 \\
\hline
\end{tabular}

Source: China City Statistical Yearbook 2009

With the rapid development of Fujian, Shandong, Tianjin, attraction of these new economic zones to immigrant population become stronger continuously, export labours from Henan, Anhui and Sichuan into Shandong during the eight years increase by 1.5 times, faster than rate of increase of Pearl River Delta region and Yangtze River Delta of absorbing immigrant population. Pearl River Delta region and Yangtze River Delta, known as a 'world factory', found itself confronted by a nearly $30 \%$ worker shortage. The worker gap in Dongguan which had more than 5 million migrant workers is over one million. Table 3 shows that immigration in selected provinces in 2000 and 2008.

Rural huge population base is obviously a crucial factor contributing to the urban population size. According to China city statistical yearbook 2009, a large part of migration took place within provinces, with population moving from rural to urban areas. Of the intra-province migrating population, 58.4\% moved from rural to urban areas during this time period. Inter-province migration was also important, with $92.6 \%$ of all inter-provincial migrants going into urban areas and almost none going to rural areas. Interprovincial flowing population mainly migrate in Guangdong, Zhejiang, Beijing, Shanghai and Jiangsu, accounting for $75 \%$ of interprovincial flowing population. Guangdong absorbs 44\% interprovincial flowing population. Zhejiang, Shanghai and Jiangsu absorbs $31 \%$. In 2008, cites in eastern area absorbed $67.4 \%$ of immigrant population, cites in middle area absorbs $16.1 \%$ of immigrant population, cites in western area absorbs $16.5 \%$ of immigrant population. Out migrating provinces with over 5 million are Henan, Anhui, Sichuan, Hunan, Guangxi, Chongqing and Hubei. The exporting labours in seven provinces account for $2 / 3$ in interprovincial flowing 
population, and labours from Henan, Anhui and Sichuan surpass 1/3. Table 7 shows population distribution between immigration and out-migration.

Table 4 Population distribution between immigration and outmigration unit: \%

\begin{tabular}{|c|c|c|c|c|c|}
\hline Outmigration & Guangdong & Zhejiang & Shanghai & Jiangsu & Beijing \\
\hline Hebei & 0.23 & 0.28 & 0.67 & 0.5 & 22.53 \\
\hline Jiangsu & 0.99 & 3.73 & 23.92 & 0 & 5.73 \\
\hline Zhejiang & 0.92 & 0 & 9.98 & 7.56 & 3.77 \\
\hline Anhui & 2.39 & 21.2 & 32.81 & 44.2 & 9.27 \\
\hline Fujian & 1.75 & 1.87 & 2.8 & 2.05 & 1.83 \\
\hline Jiangxi & 10.7 & 22.79 & 6.07 & 3.51 & 1.89 \\
\hline Shandong & 0.66 & 1.06 & 2.09 & 3.33 & 7.68 \\
\hline Henan & 6.67 & 5.39 & 3.99 & 6.52 & 13.58 \\
\hline Hubei & 9.72 & 6.65 & 2.61 & 3.8 & 4.26 \\
\hline Hunan & 22.1 & 5.36 & 1.32 & 96 & 1.52 \\
\hline Guangdong & 0 & 0.32 & 0.59 & 0.49 & 0.93 \\
\hline Guangxi & 14.69 & 0.84 & 0.2 & 0.42 & 0.32 \\
\hline Sichuan & 18.88 & 15.42 & 7.34 & 11.84 & 6.81 \\
\hline
\end{tabular}

Source: The fifth nationwide population census, China's 2000 Census Data

According to China City Statistical Yearbook 2009, in interprovincial flowing population, persons aiming at 'job' accounting for $89.5 \%$. In intraprovincial flowing population, persons aiming at 'job' accounting for $48.9 \%$.

\subsection{Region-level migration}

Since the reform and opening-up, the difference between the development of the west region and the other regions in China is increasing. In addition, the condition of the development of cities in west China needs amelioration. Li et al. (2008) concluded:

1 the growth of the GDP and per capita GDP of the western provinces is in a poor way; moreover, it is not steady going

2 the comparability among the characteristics of the urbanisation level growth of the provinces is at a low level

3 the urbanisation levels of Inner Mongolia province and Sinkiang province are more-sensitive responders to the growth of per capita GDP, whereas those of Guangxi province and Tibet province are less-sensitive responders

4 the urban population in most of the provinces are highly concentrated, which can be shown by city primary degrees and city primacy ratios.

According to China City Statistical Yearbook 2009, ratio of number of cities among eastern, ${ }^{9}$ middle, western area is 1:0.9:0.4 in 2008 and ratio of urban population is 1:0.51:0.27. City layout in the three regions from 1949 to 1998 can historically be seen in Table 5. 
Table 5 City layout in the three regions from 1949 to 1998

\begin{tabular}{|c|c|c|c|c|c|c|c|}
\hline \multirow{2}{*}{ Year } & \multirow{2}{*}{$\begin{array}{c}\text { City } \\
\text { number }\end{array}$} & \multicolumn{2}{|c|}{ Eastern China } & \multicolumn{2}{|c|}{ Middle China } & \multicolumn{2}{|c|}{ Western China } \\
\hline & & Number & $\%$ & Number & $\%$ & Number & $\%$ \\
\hline 1949 & 132 & 69 & 51.1 & 53 & 39.3 & 13 & 9.6 \\
\hline 1957 & 176 & 72 & 40.9 & 73 & 41.5 & 31 & 17.6 \\
\hline 1978 & 193 & 69 & 35.8 & 84 & 43.5 & 40 & 20.7 \\
\hline 1985 & 324 & 113 & 34.9 & 133 & 41 & 78 & 24.1 \\
\hline 1998 & 668 & 300 & 44.9 & 24 & 37 & 121 & 18.1 \\
\hline 2008 & 655 & 284 & 43.5 & 246 & 37.6 & 125 & 19 \\
\hline
\end{tabular}

On the increasing regional disparity in China, $\mathrm{Hu}$ (2002) shows that the increasing rural-to-urban labour mobility in China may be the reasons for the enlarging income gap between the coastal area and the hinterland. The income gap motivate more peasants migrate from hinterland to the coastal area. According to China City Statistical Yearbook 2009, immigrant populations in Yangtze River Delta in 2005 and 2007 are 1.07 million and 1.381 million persons. Immigrant populations in Pearl River Delta region in 2005 and 2007 are 1.848 million and 1.899 million persons. Immigrant populations in Jing-Jin-Ji region in 2005 and 2007 are 5.393 million and 4.87 million persons. Migrant labours in Pearl River Delta come both from Guangdong and the neighbouring provinces, such as Hunan, Jiangxi, Sichuan, Guangxi; Yangtze River Delta immigrant population mainly are from Anhui, Jiangxi and Sichuan. Shanghai and other 14 cites in Yangtze River Delta absorb labours from Jiangsu and Zhejiang, intraregional population flow is remarkable; intraregional Jing-Jin-Ji flow frequently, especially migration from Hebei to Beijing, Henan, Anhui is main immigrant population origins of Beijing. According to 2000 the fifth national population census, five big scale of immigrant population provinces are Guangdong, Zhejiang, Shanghai, Jiangsu and Beijing. Cities with top proportions of immigrant population in local population are Beijing, Shanghai, Guangdong, Tianjin and Zhejiang, respectively.

According to China City Statistical Yearbook 2009, interprovincial flowing immigrants in eastern region in 2000 and in 2008 are 27.28 million and 52.42 million, respectively. Interprovincial flowing immigrants in middle region in 2000 and in 2008 are 2.19 million and 2.67 million, respectively. Interprovincial flowing immigrants in western region in 2000 and in 2008 are 3.98 million and 4.07 million, respectively. In the period 1987 to 2000, intraregional (mainly intra-provincial) migration dominated, with some changes occurring as time went by. First of all, the share of inter-provincial migration within the eastern region increased, while the shares of inter provincial migration within central and western regions tended to decline. Secondly, the shares of migrations between central and western regions decreased, while inter-regional migration from the central and western regions to the eastern regions was constantly increasing (see Table 6).

Most of the migrants go to cities in the eastern coastal areas and are from the western and central inlands. While Sichuan, Henan, Anhui, Hunan and Jinagxi provinces have the largest number of emigrants, Beijing, Shanghai, Guangdong, Zhejiang and Fujian 
provinces have the highest number of immigrants. There are distinct regional patterns to the transfer and migration of rural labourers. The share of rural labourers who transferred to non-agricultural activities was higher in municipalities and coastal provinces with more prosperous economies. These regions attract a lot of migrant labourers from other provinces as their growing economies generate new jobs. In contrast, inland backward regions have limited local employment opportunities and rural labourers tend to migrate to other counties or provinces for jobs. ${ }^{10}$

\subsection{Arable land shrinkage}

The rapid expansion of Chinese cities has required the conversion of large land areas from agricultural to urban use. Since the early 1980s the conversion of land to non-agricultural use has been arguably the most widespread and intense in China's history. Among the factors contributing to these changes, rural-urban migration, urbanisation and accelerating development are among the most important. Analysis of land use data from three coastal provinces suggests that variations in the share of land occupied for non-agricultural use among county-level administrative units can be explained largely by differences in population density, urbanisation and level of development. While the conversion of land to non-agricultural use is bound to continue in the coming decade, recent institutional changes make it likely that future changes, particularly the encroachment on cultivated land, will be more restricted and better controlled (Ho and Lin, 2004). Chen (2007) concluded that China's cultivated land is shrinking at a rather shocking rate. Although conversion to urban and industrial uses took up a comparatively small share of total cultivated land loss, urbanisation should still be considered as a great threat to future agricultural production for several reasons. Urbanisation is increasing the risk of decreasing availability of cultivated land and offering unremitting efforts towards the goal of national food security in China. See Figure 2. Han (2010) shows that urban expansion is a combined outcome of actual needs, planning preparations, profit-seeking, and more importantly, the approach used by local government to achieve economic ambitions.

Figure 2 Change of China's agricultural land

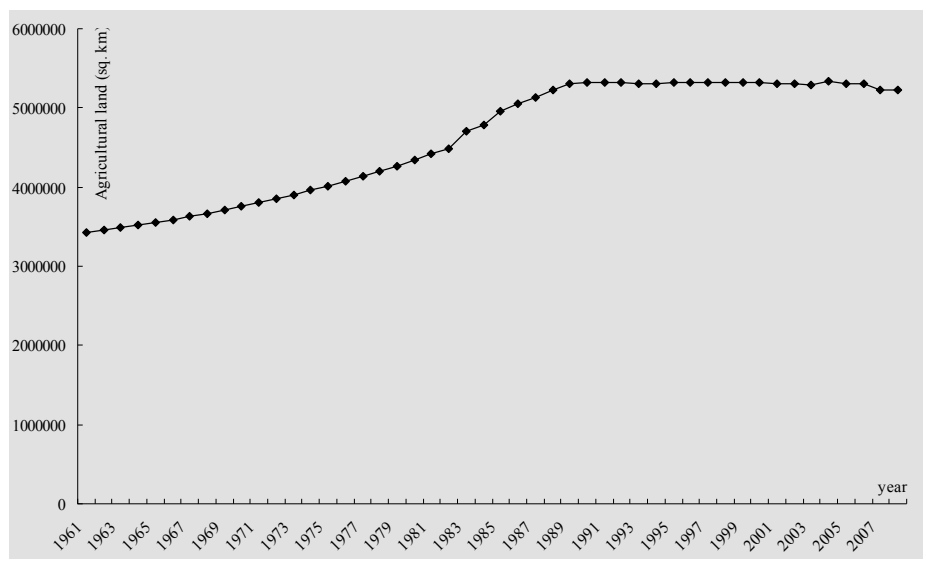

Source: Global Development Finance, The World Bank 


\section{Conclusions and implications}

In China, urbanisation is the fundamental way to balance urban and rural development and resolve issues concerning agriculture, countryside and farmers, as well as essential requirements of building a moderately prosperous society and achieving sound and rapid development. In summary, this paper review trajectory of China's urbanisation in the last six decades, focusing on urbanisation policy changes, temporal dimension and spatial dimension. The temporal evolution suggests that urbanisation under the planned economy was heavily influenced by the government's urban policy and various political movements, especially the urban resident registration policy and anti-urbanism movement such as the Culture Revolution. At that period, a very weak marketplace had almost no impacts at all on population allocation. The ideological bias against urban life as a legacy of China's peasant rebel tradition (which is an important root of the Communist Revolution), a distorted economic theory of 'recovering from economy recession through forced urban- rural relocation', and the 'one-child' family plan all contributed to lower urbanisation level. The 'controlled urbanisation' reduced pressure to urban growth, which in turn limited the expansion of urbanised land. The spatial evolution suggests that many government policy papers argue that the 'uncontrolled' expansion of cities into productive agricultural land may create food scarcity in the future. To feed its 1.3 billion population with a per capita cultivated land far below the world average, China is already facing a great challenge of land scarcity. The temporal evolution suggests that The migration process of rural labour force in China can be roughly divided into three phases: firstly, from 'migrating randomly' to 'strictly under control', from 'quitting farming to work in their hometown' to 'quitting farming to work in other regions or areas', and 'responding passively' to 'guiding actively'. Correspondingly, urbanisation in China has in part been subject to centrally planned control and in part has resulted from the pressures of industrialisation and economic development.

\section{References}

Ashton, B., Hill, K., Piazza, A. and Zeitz, R. (1984) 'Famine in China, 1958-61', Pop. Develop. Rev., Vol. 10, No. 4, pp.613-645.

$\mathrm{Au}, \mathrm{C.C.J}$. and Henderson, V. (2006) 'How migration restrictions limit agglomeration and productivity in China', Journal of Development Economics, Vol. 80, No. 2, pp.350-388.

Berg, M.M.V., Hengsdijk, H., Wolf, J., Ittersum, M.K.V., Wang, G. and Miron, R.P.J.R. (1979) 'Migration and urban economic growth', Regional Science and Urban Economics, Vol. 9, Nos. 2-3, pp.159-183.

Cai, F. (2003) Removing the Barriers to Labor Mobility: Labor Market Development and Its Attendant Reforms, 'Workshop on National Market Integration, The World Bank, Beijing Office.

Cai, F., Zhang, J. and Du, Y. (Eds.) (2002) Employment in Rural and Urban China: Issues and Options, in Chinese, Social Sciences Documentation Publishing House, Beijing.

Chan, K.W. (1992) 'Economic growth strategy and urbanization policies in China, 1949-82', International Journal of Urban and Regional Research, Vol. 16, No. 2, pp.275-305.

Chan, K.W. and Buckingham, W. (2008) 'Is China abolishing the hukou system?', The China Quarterly, Vol. 195, pp.582-606. 
Chan, K.W. and Hu, Y. (2003) 'Urbanization in China in the 1990s: new definition, different series, and revised trends', The China Review, Vol. 3, No. 2, pp.49-71.

Chan, K.W. and Xu, X. (1985) 'Urban population growth and urbanization in China since 1949: reconstructing a baseline', The China Quarterly, Vol. 104, pp.583-613.

Chan, K.W. and Zhang, L. (1999) 'The hukou system and rural-urban migration in China: processes and changes', The China Quarterly, Vol. 160 pp.818-855.

Chang, G.H. and Brada, J.C. (2006) 'The paradox of China's growing under-urbanization', Economic Systems, Vol. 30, No. 1, pp.24-40.

Chen, J. (2007) 'Rapid urbanization in China: a real challenge to soil protection and food security', CATENA, Vol. 69, No. 1, pp.1-15.

Chen, J., Guo, F. and Wu, Y. (2011) 'One decade of urban housing reform in China: urban housing price dynamics and the role of migration and urbanization, 1995-2005', Habitat International, Vol. 35, No. 1, pp.1-8.

Cheng, M.Q.S. and Ma, L. (2006) 'An explanation of the motivation and obstacles affecting rural-urban migration: the case of China', Frontiers of Economics in China, Vol. 1, No. 4, p.596.

Cheng, T. and Selden, M. (1994) 'The origins and social consequences of China's hukou system', The China Quarterly, Vol. 139, pp.644-668.

Fan, C.C. (2003) 'Rural-urban migration and gender division of labor in transitional China', International Journal of Urban and Regional Research, Vol. 27, No. 1, pp.24-47.

Fan, C.C. (2005) 'Interprovincial migration, population redistribution, and regional development in China: 1990 and 2000 census comparisons', The Professional Geographer, Vol. 57, No. 2, pp.295-311.

Fan, C.C. (2006) 'China's eleventh five-year plan (2006-2010): from 'getting rich first' to 'common prosperity', Eurasian Geography and Economics, Vol. 47, No. 6, pp.708-723.

Gaetano, A.M. and Jacka, T. (2004) On the Move: Women in Rural-to-Urban Migration in Contemporary China, 355pp, Columbia University Press, New York, IBSN 0-231-12706, ISBN 0231-12707-3 (pbk).

Gray, J. (2006) 'Mao in perspective', The China Quarterly, Vol. 187, pp.659-679.

Gu, C., Wu, L. and Ian, C. (2012) 'Progress in research on Chinese urbanization', Frontiers of Architectural Research, Vol. 1, No. 2, pp.101-149.

Gu, S. and Liu, C. (2000) Population Flow and Rural Urbanization Strategy Management, p.197, Huazhong University of Science and Technology Press.

Han, S.S. (2010) 'Urban expansion in contemporary China: what can we learn from a small town?', Land Use Policy, Vol. 27, No. 3, pp.780-787.

Ho, S.P.S. and Lin, G.C.S. (2004) 'Non-agricultural land use in post-reform China', The China Quarterly, Vol. 179, pp.758-781.

$\mathrm{Hu}, \mathrm{D}$. (2002) 'Trade rural-urban migration, and regional income disparity in developing countries: a spatial general equilibrium model inspired by the case of China', Regional Science and Urban Economics, Vol. 32, No. 3, pp.311-338.

Khan, A.R. and Riskin, C. (2005) 'China's household income and its distribution, 1995 and 2002', The China Quarterly, Vol. 182, pp.356-384.

Kim, J. (1988) 'China's modernizations, reforms and mobile population', International Journal of Urban and Regional Research, Vol. 12, No. 4, pp.595-608.

Kirkby, R.J.R. (1985) Urbanization in China, Columbia University Press, New York.

Kojma, R. (1995) 'Urbanization in China', The Developing Economies, Vol. 33, No. 2, pp.121-154.

Kueh, Y.Y. (2006) 'Mao and agriculture in China's industrialization: three antitheses in a 50-year perspective', The China Quarterly, Vol. 187, pp.700-723. 
Lavely, W. (2001) 'First impressions of the 2000 census of China', Population and Development Review, Vol. 27, No. 4, pp.755-769.

Lee, Y.F. (1989) 'Small towns and China's urbanization level', The China Quarterly, Vol. 120, pp.771-786.

Li, B. and Piachaud, D. (2006) 'Urbanization and social policy in China', Asia-Pacific Development Journal, Vol. 13, No. 1, pp.1-26.

Li, Z., Yang, Y. and Liu, Y. (2008) 'Difference among the growth of GDP and urbanization of the provinces and the cities in west china since the reform and opening-up: China population', Resources and Environment, Vol. 18, No. 5, pp.19-26.

Lin, G.C.S. (1993) 'Small town development in socialist China: a functional analysis', Geoforum, Vol. 24, No. 3, pp.327-338.

Lin, G.C.S. (2002) 'The growth and structural change of Chinese cities: a contextual and geographic analysis', Cities, Vol. 19, No. 5, pp.299-316.

Lin, J.Y. and Yang, D.T. (2000) 'Food availability, entitlements and the Chinese famine of 1959-61', Economic Journal, Vol. 110, No. 460, pp.136-158.

Liu, S. et al. (2003) Scenario Analysis on Urbanization and Rural-urban Migration in China, Interim Report, IR-03-036.

Liu, Y., He, S. and Wu, F. (2010) 'Chris Webster: urban villages under China's rapid urbanization: unregulated assets and transitional neighbourhoods', Habitat International, Vol. 34, No. 2, pp.135-144.

Naughton, B. (1988) 'The third front: defense industrialization in the Chinese interior', China Quarterly, Vol. 115, pp.351-386.

Peng, X. (2004) 'Is it time to change China's population policy?', China: An International Journal, Vol. 2, No. 1, pp.135-149.

Riskin, C. (1987) China's Political Economy, Oxford University Press, New York.

Schoppa, K.K. (2000) The Columbia Guide to Modern Chinese History, Columbia University Press.

Shen, J., Feng, Z. and Wong, K.Y. (2006) 'Dual-track urbanization in a transitional economy: the case of Pearl River Delta in South China', Habitat International, Vol. 30, No. 3, pp.690-705.

Shen, J.F. (1995) 'Rural development and rural to urban migration in China 1978-1990', Geoforum, Vol. 26, No. 4, pp.395-409.

Sit, V.F.S. and Yang, C. (1997) 'Foreign-investment-induced exo-urbanization in the Pearl River Delta, China', Urban Studies, Vol. 3, No. 4, pp.647-677.

Sun, J.Z. (Ed.) (1996) Analysis on China's Population Change in 1980s, pp.86-87, China Finance Press, Beijing.

Wang, B., Li, X., Stanton, B. and Fang, X. (2010) 'The influence of social stigma and discriminatory experience on psychological distress and quality of life among rural-to-urban migrants in China', Social Science \& Medicine, Vol. 71, No. 1, pp.84-92.

Wang, F.L. (2005) Organizing Through Division and Exclusion: China's Hukou System, Stanford University Press, Stanford, CA.

Wong, D.F.K. et al. (2007) 'Rural migrant workers in urban China: living a marginalised life', Int. J. Soc. Welfare, Vol. 16, pp.32-40.

Woo, W.T., Hai, W., Jin, Y. and Fan, G. (1994) 'How successful has Chinese enterprise reform been? Pitfalls in opposite biases and focus', Journal of Comparative Economics, Vol. 18, No. 3, pp.410-437.

Wu, H.X. (1994) 'Rural to urban migration in the People's Republic of China', The China Quarterly, Vol. 139, pp.669-698.

$\mathrm{Wu}, \mathrm{Z}$. (2010) 'Self-selection and earnings of migrants: evidence from rural China', Asian Economic Journal, Vol. 24, No. 1, pp.23-44. 
Xian, Z. (Ed.) (2001) Construction of Small Cities and Towns and Immigration of Rural Labor, in Chinese, China Statistic Press, Beijing.

Xu, X.Q., Zhou, Y.X. and Ning, Y.M. (1999) Urban Geography, p.43, Higher Education Press, Beijing.

Yang, D.L. (1996) Calamity and Reform in China: State, Rural Society, and Institutional Change Since the Great Leap Famine, Stanford University Press, Stanford, Calif., USA.

Yeh, A.G. and $\mathrm{Xu}, \mathrm{X}$. (1984) 'Provincial variation of urbanization and urban primacy in China', The Annals of Regional Science, Vol. 23, No. 3, pp.1-20.

Yu, D. (2002) Chengxiang Shehui: Cong Geli Zouxiang Kaifang: Zhongguo Huji Zhidu Yu Hujifa Yanjiu City and Countryside Societies: from Segregation to Opening: Research on China's Household Registration System and Laws, Shandong Renmin Chubanshe, Shandong People's Press, Jinan.

Zhang, K.H. and Song, S. (2003) 'Rural-urban migration and urbanization in China: evidence from time-series and cross-section analyses', China Economic Review, Vol. 14, No. 4, pp.386-400.

Zhang, L. (2008) 'Conceptualizing China's urbanization under reforms', Habitat International, Vol. 32, No. 4, pp.452-470.

Zhang, L. and Zhao, S.X. (2003) 'Reinterpretation of China's under-urbanization: a systemic perspective', Habitat International, Vol. 27, No. 3, pp.459-483.

Zhang, L. and Zhao, S.X.B. (1998) 'Re-examining China's 'urban' concept and the level of urbanization', The China Quarterly, Vol. 154, pp.330-381.

Zhang, Z. (1991) 'The economic advantages of large cities: a case study of China's urban centres', Habitat International, Vol. 15, No. 4, pp.171-181.

Zhao, S.X.B., Chan, R.C.K. and Sit, K.T.O. (2003) 'Globalization and the dominance of large cities in contemporary China', Cities, Vol. 20, No. 4, pp.265-278.

Zhao, Y. (2003) 'The role of migrant networks in labor migration: the case of China', Contemporary Economic Policy, Vol. 21, No. 4, pp.500-511.

Zhou, Y. and Ma, L.J.C. (2003) 'China's urbanization levels: reconstructing a baseline from the fifth population census', The China Quarterly, Vol. 173, pp.176-196.

\section{Notes}

1 A person's local 'citizenship' and residence is initially defined for a child as a birth right, traditionally by the mother's place of legal residence. The entitlements and details of the system differ for urban and rural residents. Legal residence in a city entitles one to local access to permanent jobs, regular housing, public schooling, and public health care (where almost all health care is public) in that city. Until the early 1990s, it also entitled urban people to 'grain rations' - rations of essentials such as grain and kerosene. Legal residence in a village or rural township entitles residents to land for farming, township housing, and job opportunities in rural industrial enterprises, and access to local health and schooling facilities in their town.

2 China's urban system operates on a strict administrative hierarchy: provincial-level cities, provincial capitals, other prefecture-level cities, and county cities. There are two distinctive features. First, higher-level cities 'oversee' the governance of low-order ones. Second, cities higher in the hierarchy are favoured in important ways: greater autonomy in decision making, more public finance resources, greater access to transport corridors and rail capacity, etc. Many small cities and rural areas have insufficient fiscal capacity to fund public services properly. Bigger cities appear to have greater access to 'off-budget' revenues, and some enjoy conspicuously high levels of public infrastructure investment funded by the centre.

3 Enrolment in China's higher education institutions was suspended between 1966 and 1976, the period of the Cultural Revolution. Nationwide college entrance examination was resumed in 1977. 
4 Women constitute a significant proportion of the migrant population in China. Gaetano and Jacka (2004) presents a clear picture of the experiences and lives of rural-to-urban migrant women before and after their migration, outlining how they started their new lives as migrant workers in cities, how they found jobs there, and how important initial help from their relatives and fellow villagers in cities was to them. It shows the kinds of abuse, contempt, humiliation, harassment, exploitation and threats which were often meted out to them by employers and co-workers, and how they coped with such difficulties and survived. It also covers the uses to which they put their wages. In many cases the women gained a sense of independence and value, acquired new skills, and absorbed new ideas about love and marriage through migration.

5 Chinese researchers estimated that about 150 million peasants have migrated to cities since the 1980 s, and $20 \%$ to $25 \%$ of the migrants eventually become 'permanent urban residents' while the rest maintain a come-and-go 'floating' pattern. Natural population growth in cities has limited impacts on urban population change, and it even shows negative figures in big cities.

6 'Harmonious society' ('hexie shehui') is a concept that was introduced by President Hu Jintao of the People's Republic of China (PRC) as a vision or objective for the country's future socioeconomic development. After his succession to power in 2002, Hu presented this concept and a related idea, the 'scientific development concept' ('kexue fazhan guan'), as the unifying concepts of his administration.

7 Wang et al. (2010) conclude that perceived social stigma and daily discriminatory experiences have a significant influence on psychological distress and quality of life among rural-to-urban migrants. Pre-migration training with a focus on establishment of effective coping skills and preparation of migration may be helpful to improve their quality of life and mental health.

8 The urban village is considered as a community of interest for urbanized villagers, a migrant settlement with low-rent housing, and an urban self-organized grassroots unit, respectively related to the ambiguous property rights, an informal rental market, and the vacuum of state regulation. The urban village is therefore viewed as an unregulated asset despite its unruliness and disorder. Meanwhile, the formation and dynamics of the urban village are understood from the perspectives of land use transformation and property rights redistribution, with an additional emphasis on the succession of traditional social norms and networks.

9 The East China covers her most developed areas including the 'three engines to China's economy': the Pearl River Delta, the Yangtze River Delta, and the Beijing-Tianjin - Tangshan Region, and three main metropolitan areas of Beijing, Shanghai, and Hong Kong/Guangzhou where the majority of the population are in urbanised areas and the economy is in transition to a mixed of manufacturing and service industries.

10 In comparison with other developing countries, rural migrants to cities in China are discriminated against as a matter of policy, leading to dualism within urban society, as well as between urban and rural society. They have little to no access to formal sector housing markets and live in dormitories or in the informal sector rental market in 'urban villages' within and concentrated in the outskirts of cities. In China, most migration is temporary, or 'round-trip', despite the irreversible march to full urbanisation. Non-portability of wealth limits the ability of migrants to buy urban housing, invest in urban businesses, and integrate into urban civil society. 